\title{
Prospective Comparison of Osteoporotic Vertebral Fracture Treatment
}

\author{
Schupfner Rupert ${ }^{1 *}$, Pfeifer, Christian ${ }^{2}$ and Müller Michael ${ }^{1}$ \\ ${ }^{1}$ Department of Traumatology, Hospital Bayreuth, Germany \\ ${ }^{2}$ Department of Traumatology, University Hospital Regensburg, Germany
}

Submission: May 03, 2020; Published: May 11, 2020

*Corresponding author: Rupert Schupfner, Klinik für Unfall- und Wiederherstellungschirurgie, Klinikum Bayreuth, Preuschwitzerstr 101 95445, Bayreuth, Germany

\section{Abstract}

Introduction: Thoracolumbar osteoporotic vertebral fractures often occur in elderly patients. Possible treatment options include conservative therapy with orthoses and minimally invasive therapies like balloon kyphoplasty. Studies show advantages in pain reduction post-kyphoplasty. In contrast, activating orthoses seem to have a longer-term positive effect on muscles and thus the sagittal plane of the spine.

Aim: This prospective comparative study was designed to investigate differences regarding pain relief, mobility, quality of life and radiologic changes in a patient population with osteoporotic vertebral fractures between Th 9 and L5.

Patients and Methods: Patients were assigned to individual groups based on the inclusion and exclusion criteria listed here. 30 patients were treated only with kyphoplasty, 30 conservatively with the aid of a Spinomed orthosis, and 30 with a combination of the two approaches. After baseline examination and group assignments, data was collected within one week, after three months and after six months. Pain intensity was measured on a visual analogue scale of zero to ten. The SF-12 questionnaire was used to record quality of life; the definition of everyday activities was based on Leidig-Bruckner. In addition, the kyphotic angle of the adjacent superior and inferior endplates was measured. In all follow-up examinations, conventional X-rays were taken as well as a personal examination of the patient, including questions and filling in the standardised form to record intensity of pain, mobility, and quality of life.

Results: 90 patients in total (female $=61$, male $=29$ ) with osteoporotic vertebral fractures were included, 30 of which were each were assigned to the groups of Kyphoplasty, Spinomed, or Kyphoplasty and Spinomed. It was possible to follow-up $87 \%$ ( $=78$. All covariance analyses such as age, BMI and gender showed no influence on the results. For the Kyphoplasty group, the evaluation of pain perception showed a significant improvement in pain directly following care. After six months, pain lowered considerably for all three treatment groups. A comparison of domestic activities showed no significant improvement in any of the three groups. The level of improvement of quality of life was approximately the same for all three groups. It was striking that good straightening of the kyphotic angle was possible as early as by the day of discharge following kyphoplasty. Additionally, wearing an activating orthosis had a significantly better facilitating effect on maintaining this angle following discharge.

Conclusion: Balloon kyphoplasty results in a faster improvement in pain. When used in combination with an activating orthosis, the therapy has a positive effect on long-term vertebral straightening and thus also the sagittal plane of the spine. There is no significant effect on quality of life.

Keywords: Osteoporotic vertebral compression fracture, Minimal invasive treatment, Orthesis

\section{Introduction}

Vertebral compression fractures (VCF) are frequent manifestations of osteoporosis. The global incidence of new cases of osteoporotic vertebral compression fractures (OVCF) is estimated at 550,000 to 700,000 annually. The exact incidence is difficult to pinpoint, as only $23-33 \%$ of these fractures are clinically confirmed [1]. Patients may experience prolonged pain and increasing kyphosis due to changes to the structure of the spine. This can result in a higher risk of additional adjacent fractures and impaired lung function. For many individuals affected, the lasting, gruelling pain symptoms and resultant 
comorbidity lead to severe mobility problems with associated limited quality of life [2]. In addition, patients with untreated osteoporotic vertebral fractures have a $23 \%$ higher 5-year mortality rate in comparison to a control group without vertebral fractures [3]. A variety of therapeutic strategies are available for OVCF. These include conservative therapies with analgesics and bedrest and/or corset treatment for mobilisation, minimally invasive methods, and complex stabilising operations to the spine. Choosing the right treatment is dependent on many different factors. Various algorithms are available to support appropriate treatment choice $[4,5]$. Many studies have shown that minimally invasive procedures such as balloon kyphoplasty (BKP) and vertebroplasty (VP) significantly reduce pain [6]. In the short term, it has also been possible to demonstrate good correction of both radiographic measurements and monosegmental kyphosis angles.

Further progression often resulted in a loss of correction which was sometimes reflected in the level of activity, and therefore the quality of life, of the patient. Regarding this, while functional conservative therapy using an activating corset did result in pain reduction, but the initial effect was low. However, treatment with activating orthoses reduces kyphotic deformity in the long run [7]. The objective of the study was to test to what extent a combination of both procedures would demonstrate an advantage over the use of just one of the procedures. Studies on combination treatments are lacking. Our study investigates the effectiveness and tolerability of the combination of balloon kyphoplasty and activating orthosis instead of choosing only one treatment.

The treatment options to be compared in this study are:

\section{Conservative Therapy}

Conservative functional therapy for vertebral fractures typically comprises a short period spent in a prone position until pain fades, followed by an upright phase involving targeted physical therapy. This phase is supported by functional training in sitting and walking correctly.

Traditional corsets such as three-point or four-point surgical corsets are generally less well appreciated because of their lack of comfort, atrophying effect of the back muscles in response to immobilisation and post-traumatic stiffening of the vertebral joints. Activating orthoses are therefore usually more preferred. These are intended to encourage and activate the musculature of the back and abdomen. The upper body is held erect effectively. Via a back brace, biofeedback with flexible materials exerts noticeable tension on the pelvic and shoulder girdles, which gently corrects poor or worsening posture resulting from kyphosis. The patient reflexively tenses his back and torso muscles, thereby using his own muscle strength to straighten the upper body. This actively strengthens the musculature; the upright posture compensates for deep breathing, thereby reducing the negative effects on the thorax and abdominal organs (Figure 1). However, it is not possible to prevent the collapse of the vertebra under strain, even with an activating bodice [7].

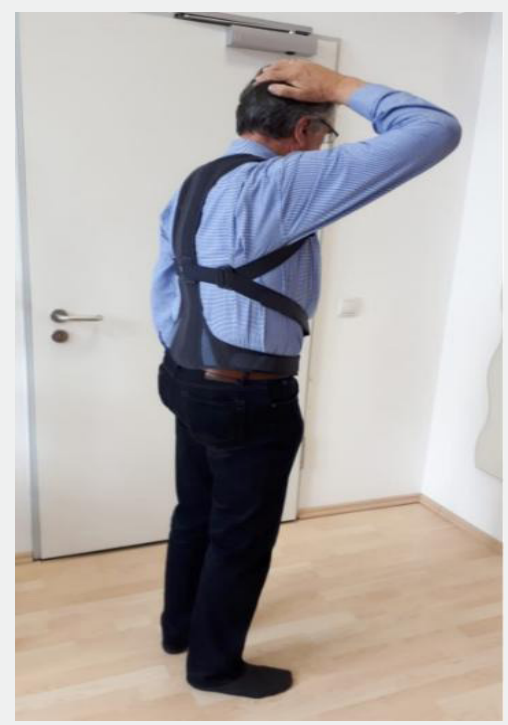

Figure 1: conservative therapy by wearing an activating orthosis.

\section{Minimally Invasive Operative Therapy}

Kyphoplasty and vertebroplasty are minimally invasive percutaneous procedures. In the case of vertebral fractures, cement is applied to one or both pedicles under radiological monitoring [8]. In contrast to vertebroplasty, kyphoplasty involves the initial insertion of a balloon. The balloon is expanded to produce a cavity which is filled with bone cement [9] (Figure 2). 


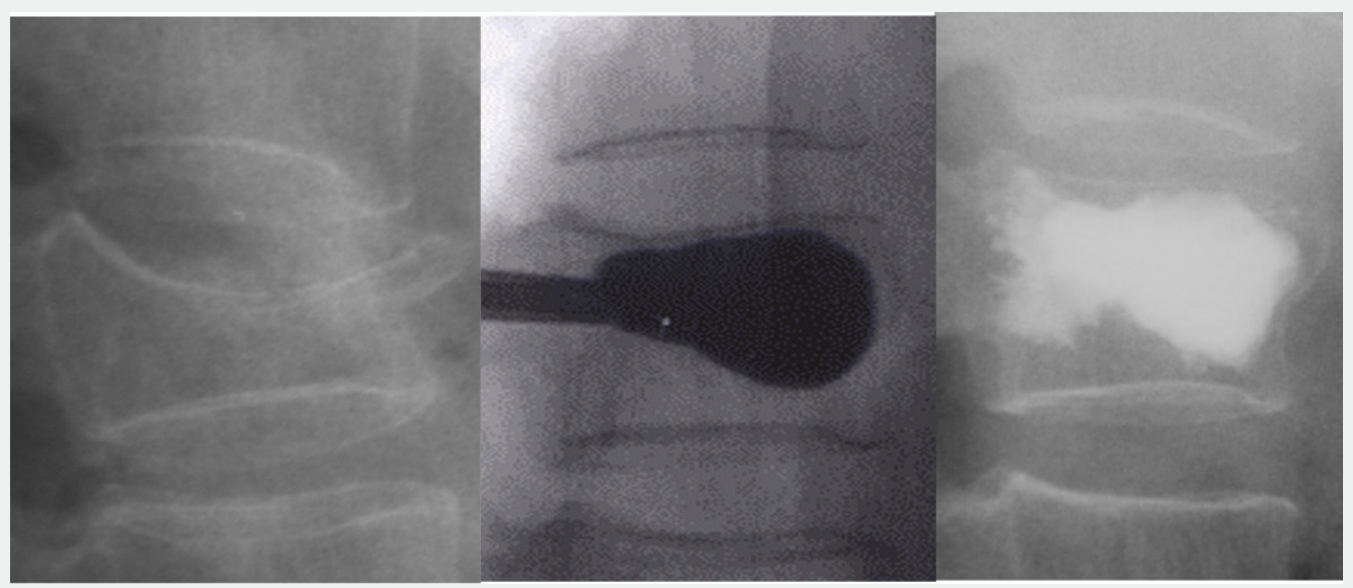

Figure 2: Minimal invasive operative therapy.

The objectives of balloon kyphoplasty are to restore the original height of the fractured vertebra and to counteract the progressive deformation of the spine along the sagittal plane, in other words, the kyphosis in the thoracic area [10]. Another advantage of balloon kyphoplasty is the fact that, by creating a cavity, cement can be instilled in the vertebra using a significantly lower level of injection pressure, which makes it less likely that cement will leak [11].

\section{Combination of both therapy options}

There are no studies about the combination of balloon kyphoplasty and the use of an activating orthoses.

Materials and Methods

\section{Patient Selection}

Table 1: Patient selection criteria.

\begin{tabular}{|c|c|}
\hline $\begin{array}{c}\text { Inclusion criteria } \\
\text { Osteoporotic vertebral } \\
\text { fractures }\end{array}$ & Exclusion criteria \\
\hline Th 9 to L5 & Kyphosis over $30^{\circ}$ as per Cobb \\
\hline & Recent neurological deficit \\
\hline & $>3$ vertebra affected \\
\hline
\end{tabular}

90 patients with an osteoporotic vertebral fracture of at least Grade I according to the definition of the Fatherland Osteologie (DVO), a German organisation for osteology, were included. Selection criteria are listed in Table 1. All patients were referred to the Department for othopedic and trauma surgery of Klinikum Bayreuth with an osteoporotic vertebral compression fracture between March 2014 and December 2017. The diagnostic evaluation at intake included detailed medical history, physical examination and imaging by $\mathrm{x}$-ray and MRI. The principal inclusion criterion was a recent OVCF of Th9 to L5. Patients were only accepted into the study if the STIR (short-tau inversion recovery) sequence showed an increased accumulation. This increased accumulation was considered a sign of relatively recent pathology in the context of the fracture oedema.

For all patients, fracture morphology, fracture height and care strategy were recorded along with sociodemographic factors such as age and gender. In the first examination and anamnesis, the type and date of the trauma or duration of the complaints were assessed. This included information about individual comorbidities and risk factors. Included patients suffered from significant back pain with sensitivity to pressure and percussion, usually in the thoracolumbar fascia. In addition to the obligatory plain X-rays that were used to classify the fracture, three-dimensional imaging (CT and /or MRI) was conducted. Neurological symptoms or an impression of the spinal canal was an exclusion criterion.

\section{Patients were offered three treatment options:}

$$
\begin{aligned}
& \text { A: conservative care using a Spinomed orthosis. } \\
& \text { B: BKP } \\
& \text { C: BKP + Spinomed orthosis. }
\end{aligned}
$$

Assignment to either group was a shared decision between the patient and the physician. Patients were assigned to the different groups after explaining the treatment options by shared decision between the patient and the physician. The choice of using an orthosis was merely based on explaining its potential advantages and drawbacks. The shared decision approach was chosen because previous studies have shown that compliance and motivation are major drivers of success of using an orthosis.

At baseline $(\mathrm{T}=0)$ the following data were recorded:
i. Pain score (VAS)
ii. Level of activity (Leidig-Bruckner) 


\section{Orthopedics and Rheumatology Open Access Journal (OROAJ)}

iii. Quality of life (SF36)

iv. Monosegmental kyphosis angle

v. At discharge ( $\mathrm{T}=1$, usually 2 days after admission)

vi. At 6 weeks $(\mathrm{T}=2)$

vii. At 6 months $(\mathrm{T}=3)$

Follow-up included: remeasurement of VAS, level of activity, SF 12 , X-rays. The first follow-up examination occurred immediately after the operation or fitting of the back orthosis by an orthopaedic technician. Quality of life in terms of health was examined using a standardised questionnaire (SF-12). This questionnaire is an established tool for collecting data on the general quality of life in terms of health. In addition to the questionnaire, which patients filled in themselves, a VAS (visual analogue scale) was used to record the level of pain. Furthermore, the level of activity (as per Leidig-Bruckner) was recorded and control X-rays were taken [12]. Here, the monosegmental kyphosis angle was calculated using defined film-focus distance. This corresponds to the angle between the inferior endplate of the fractured vertebra and the superior endplate of the cranial vertebra above it in lateral projection.

Our study was conducted in accordance with the Declaration of Helsinki and approved by ethics committee of the university of Erlangen. All test subjects were permitted to withdraw their consent to participation in the study without stating the reason without any negative consequences for their continued medical care.

\section{Statistical Analysis}

All data were collected and analysed pseudononymously. IBM SPSS Statistics 24 was used for the statistical evaluation. The results were presented as mean plus/minus SD. Student's t-test was used to identify a significant difference between the measurement of VAS score, kyphotic angle and QoL for each group. The independent t-test was used to identify significant difference between the groups. In all analyses, p value $<0.05$ was considered statistically significant.

Results

In total 90 patients were included, similarly divided over the 3 treatment arms. However, it was only possible to subsequently monitor 29 complete conservative treatments, 26 patients receiving only kyphoplasty, and 23 patients receiving both kyphoplasty and Spinomed orthoses (Table 2). Incomplete followup examination results were assessed as dropouts. Two patients died while the study was underway; according to their attending physicians, in both cases this was not related to the vertebral fracture. The other missing follow-up examinations can be explained in part by the age of the patients, as in some cases there was major comorbidity and/or limited mobility to such an extent that the patients were unable to attend the follow-up examination.
The data set that was processed consists of 78 valid data sets. Data were collected from 52 women and 26 men.

Table 2: Baseline demographics.

\begin{tabular}{|c|c|c|c|}
\hline Therapy & Female & Male & Number \\
\hline Kyphoplasty & 18 & 8 & 26 \\
\hline $\begin{array}{c}\text { Kyphoplasty and } \\
\text { Spinomed }\end{array}$ & 16 & 7 & 23 \\
\hline Spinomed & 18 & 11 & 29 \\
\hline Number & 52 & 26 & 78 \\
\hline
\end{tabular}

The following table 3 shows the median age and median BMI for the entire data set:

Table 3: Baseline demographics.

\begin{tabular}{|c|c|c|}
\hline Therapy & $\begin{array}{c}\text { Average age in } \\
\text { years }\end{array}$ & Average BMI \\
\hline Kyphoplasty & 79.3 & 26.6 \\
\hline Kyphoplasty and Spinomed & 77.6 & 27.4 \\
\hline Spinomed & 72.3 & 25.2 \\
\hline Overall result & 76.2 & 26.3 \\
\hline
\end{tabular}

Younger patients tended to be more willing to wear an activating orthosis. However, this did not depend on their BMI.

Follow-up

The immediate effect $(\mathrm{T}=1)$ of the various treatment options on the pain score (VAS) is shown in Figure 3. Patients receiving kyphoplasty showed a significantly higher improvement in pain level in comparison to conservative therapy. Pain perception was also shown to vary from individual to individual. Illustrating the parallel coordinates plots as individual progressions resulted in a large number of very different progressions. Overall, no visible pattern nor uniform change emerged upon evaluation. Only the depiction of the average values produced uniform, clear lines with distinct differences. A pairwise comparison of the pain score (separated by therapy group) only demonstrated a significant difference in the kyphoplaty group for the comparison between $\mathrm{T} 0$ and $\mathrm{T} 1$.

All covariance analyses including BMI, age, gender, and therapy did not show a significant role on pain and quality of life measures (Table 4). When pain scores were compared at T3, there was no significant difference. (Figure 4). If only the difference between T1 and T3 is considered, then it appears that the long-term effect for Spinomed therapy is not significantly better. Overall, there were no significant difference between the therapy options for the different group in terms of pain relief and quality of life. 


\section{Orthopedics and Rheumatology Open Access Journal (OROAJ)}

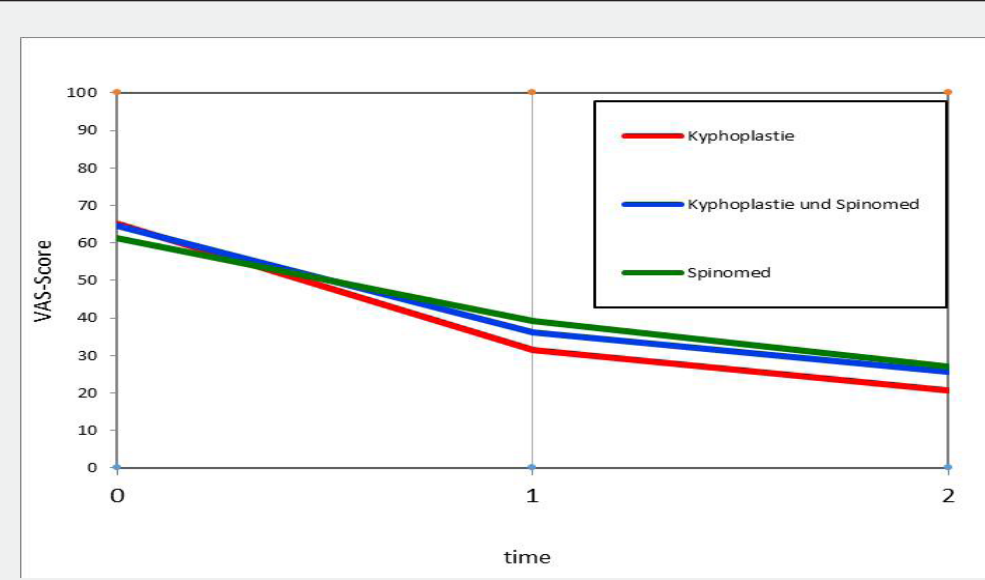

Figure 3: Pain development over time in the different treatment groups.

Table 4: Covariance analyses for pain.

\begin{tabular}{|c|c|c|c|c|c|}
\hline Source & DF & Sum of Squares & Mean Squares & F & Pr $>$ F \\
\hline BMI & 1 & 69.089 & 69.089 & 0.218 & 0.642 No Influence \\
\hline Gender & 1 & 167.886 & 167.886 & 0.530 & 0.469 No Influence \\
\hline Age in Years & 1 & 1152.277 & 1152.277 & 3.774 & 0.056 No Influence \\
\hline
\end{tabular}

The total values of PCS (physical composite scores; questions regarding physical limitations) and MCS (mental health composite scores; questions regarding mental health limitations) depict the results of the SF-12 questionnaire. These can easily be compared with a normal population of the corresponding age and a reference group with osteoporosis. When comparing quality of life for the individual treatment groups, our study population displayed a considerable reduction in quality of life in terms of both PCS and MCS (Table 5). Overall, at every examination date, the SF-12 scores overlap greatly, and composite scales are approximately the same as the individual examination times, depending on the form of therapy.

Table 5: Results on quality of life (Evaluation of the SF-12 questionnaire for the patients examined, in comparison with a reference population of the corresponding age for patients with osteoporosis.

\begin{tabular}{|c|c|c|}
\hline & Physical composite scale SF-12 Average (SD) & Mental health composite scale SF-12 Average (SD) \\
\hline $\begin{array}{c}\text { German representative sample > } \\
\text { years old }\end{array}$ & $41.69(12.1)$ & $52.44(9.90)$ \\
\hline Osteoporosis patients (1998) & $39.03(10.86)$ & $49.56(10.55)$ \\
\hline Kyphoplasty at T3 & $31.69(9.44)$ & $40.87(10.14)$ \\
\hline Kyphoplasty and Spinomed at T3 & $99.93(8.72)$ & $42.61(9.04)$ \\
\hline Spinomed at T3 & $30.93(9.09)$ & $41.62(8.04)$ \\
\hline
\end{tabular}

Wearing an orthosis resulted in less collapse of the vertebral body. In the groups with application of a Spinomed orthosis, both as a sole therapy and following kyphoplasty, there was no additional vertebral collapse over time (T1 to T3). Here, the twostage t-test of the hypothesis that the difference between the average values would be close to zero demonstrated significance, confirming the hypothesis (Figure 5) (Table 6). In contrast, for solely kyphoplasty, the t-test displayed a lower p-value below the significance level of $\mathrm{p}=0.05$, meaning the null hypothesis had to be rejected. The alternative hypothesis - that the average values would be significantly different and thus point to an accumulated collapse - had to be accepted (Figure 6). 


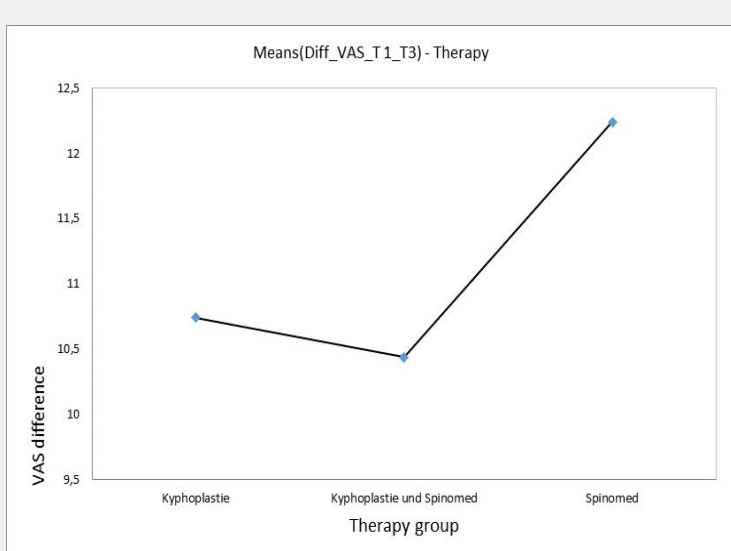

Figure 4: Mean pain difference T1 to T3.
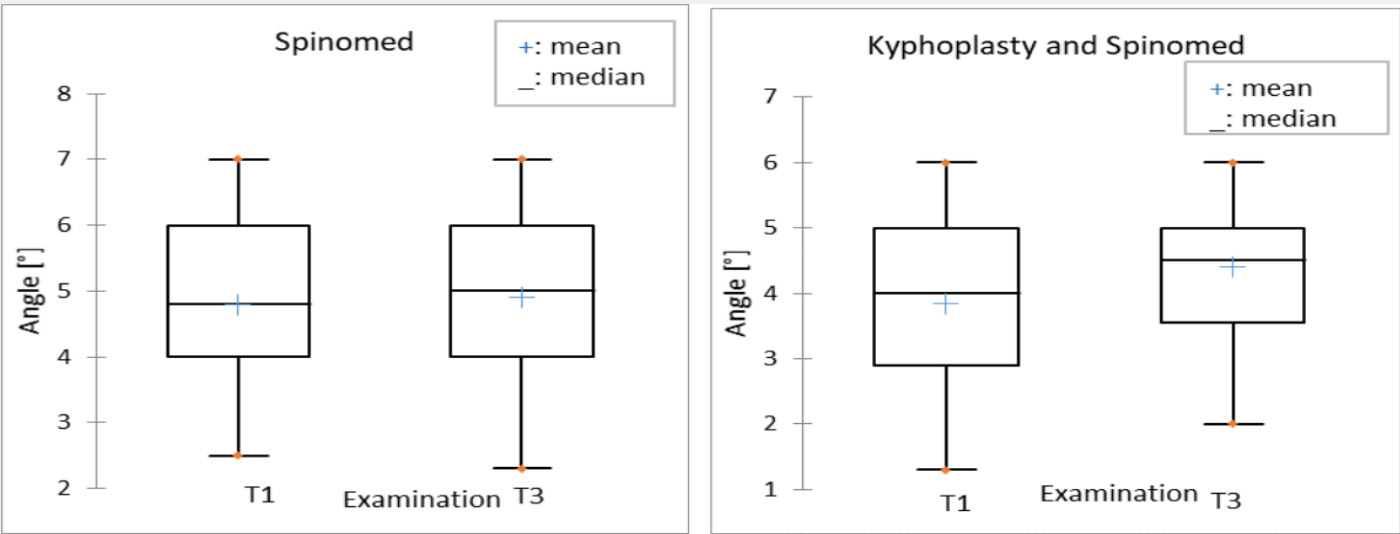

Figure 5: Collapse of vertebral body Boxplots with median, mean (blue + sign) and Tukey whiskers.

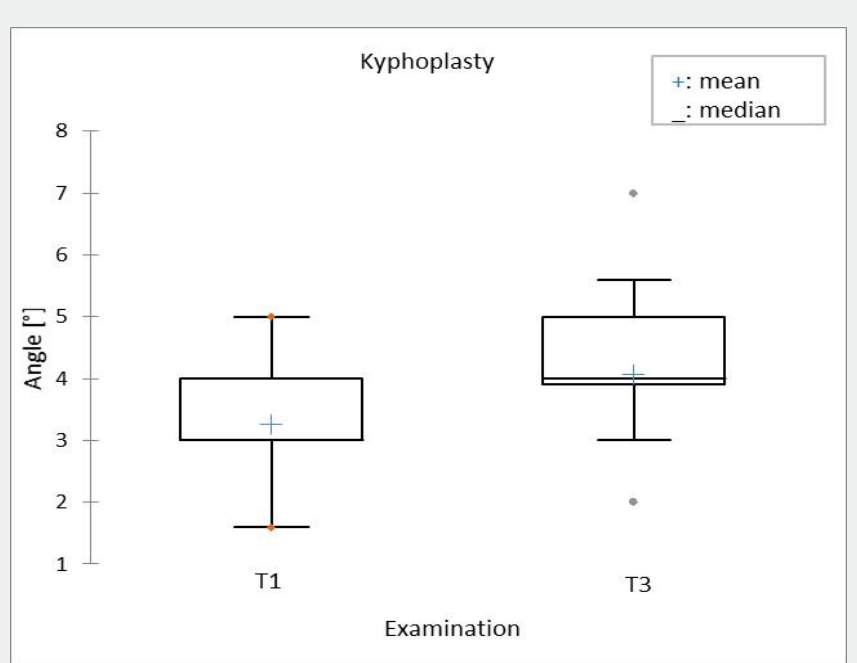

Figure 6: Collapse of vertebral body Boxplots with median, mean (blue + sign) and Tukey whiskers. Grey points symbolize outliers (outside Tukey whiskers). 


\section{Orthopedics and Rheumatology Open Access Journal (OROAJ)}

\section{Discussion}

With respect to its design, this study may be described as a prospective, unicentric, uncontrolled cohort study. Only osteoporotic vertebral fractures were included in the study. Division into the treatment groups occurred in consultation with the patients, as the willingness of wearing the activating back orthosis is an important predictor of actual compliance. As BKP is only recommended for cases of stable vertebral compression fractures without symptoms of neurological malfunction, the area of application corresponds to a population of patients who can be treated conservatively. For this reason, when assigning patient groups, high levels of patient compliance was considered especially important. Incorporating the patients into therapeutic decisions in this way resulted in very high rates of patients wearing the Spinomed orthoses. For future studies, it would be beneficial to digitally track the duration of wearing the orthosis for example via the orthosis' closure. This would make it possible to disregard the compliance aspect when assigning patients to the individual treatment groups.

Psychological guidance for the patients and their compliance is particularly important for the therapy using orthoses. When worn, the orthosis initially lends a feeling of security that leads to a lasting improvement in body posture. Even after the orthosis is removed, this improvement remains thanks to muscle memory. In comparison to earlier corset treatments, activating corsets like the Spinomed orthoses demonstrate positive effects and strengthening of the back and abdominal musculature, improved posture and a diminished tendency to sway, as well as correspondingly improved overall quality of life including pain reduction and an improved sense of well-being [13].

The fact that all operative treatments of the study patients were performed by just one surgeon can be considered positive, as this allowed the study to avoid individual differences in OP technique. Nevertheless, this fact also presents a potential bias. The SF-12 is a concise, abbreviated version of the SF-36 and comprises 12 selected items from the full questionnaire. It is a valid measuring instrument used to record quality of life in terms of health and thus the success of the therapy [14]. Evaluation of the SF-12 data produces two composite values. One of these values indicates the quality of life in terms of mental health (MCS) [15]; the other denotes the quality of life in terms of physical health (PCS). Higher values correspond to a better outcome. As the coefficients used for the weighting were based on the work of Gandek et al. [16] comparing the results with American data is only possible to a limited extent.

The generally relatively low composite scales can be traced back to the high average age of the population under examination, one that has a relatively high incidence of comorbidity. This is since the study did not apply any exclusion criteria for accompanying diseases. For the physical composite scale (PCS), evaluation of the SF-12 questionnaire showed a tendency towards better quality of life following kyphoplasty and Spinomed treatment, with no verified statistical correlation.

Typical osteoporotic vertebral fractures are characterised by a collapsed superior or inferior endplate with vertebral height loss, usually associated with wedge-shaped deformity. Biomechanical studies have shown that when the anterior or posterior weightbearing elements in the spine are damaged, itcan resultin curvature to the spine. Wedge-shaped deformations appear on various levels. This leads to a shift in centre of gravity, which increases the flexion momentum. Progressive kyphosis is responsible not only for cosmetic deficits, but also for physiological and neurological ones. This can result, for example, in compression of the thoracic and abdominal organs, affecting lung capacity and bowel mobility. The minimally invasive treatment of the spine is intended to stabilise the sagittal plane of the spine and thus reduce pain and improve quality of life. Nevertheless, over the course of time the vertebra may relapse from the correction. Although a good level of pain reduction was apparent immediately post-operation, this had no effect on the quality of life indicated in the SF-12. The mobility index also showed little change. At T3, it was not possible to confirm the majority of treated patients who had experienced an initial restoration in vertebral height and associated improvement to the kyphotic angle at T1.

Some studies found that kyphotic reduction was lasting, over a period of 12 months, following kyphoplasty [17]. Yet there are also studies that were able to prove further collapse or renewed loss of correction. In his study, Pfugmacher found that there was a drop in vertebral height after 12 months [18]. This progressive loss of height can be explained by normal settling processes and seems to be independent of the type of cement used. This effect has also been demonstrated in conservatively treated vertebral fractures. At this point, we would like to emphasise the importance of muscle activation and of biofeedback. The aim of treating a vertebral fracture is to optimally restore static and dynamic function in the spine.

Achieving this requires approximate restoration of the anatomical shape, as well as maintaining or restoring neurological integrity and stability in the spine. It is not currently possible to derive a sufficient causal explanation for the loss of correction occurring after six months for most of our study's patients based on the data at hand. Possible causes include persistent osteoporosis in the peripheral areas of the affected vertebra or secondary reconstructive processes as part of remodelling in the case of both conservatively and surgically treated fractures. No groups were able to completely avoid collapse of the fractured vertebra over the course of treatment. However, our study shows that there is no correlation between the radiologically proven vertebral deformities and the patient's level of pain in the VAS score and their quality of life in the SF-12.

Our study did not demonstrate any significant differences regarding age, gender, or BMI. For this reason, it is not possible 


\section{Orthopedics and Rheumatology Open Access Journal (OROAJ)}

to derive a definitely optimal therapy for a patient from biological and sociodemographic data alone. Instead, the success of the therapy depends on the trust the patient places in the chosen therapy. The MCS results from the SF-12 support this theory that there is no significant difference between the therapy groups. The freedom to choose their treatment, in addition to being provided with an orthosis, was well received by patients. The explanations regarding these therapeutic choices were met with relatively high levels of satisfaction with the conditions of life resulting from their respective decision from both the patients who were consciously in favour of as well as those who consciously were against the provision of an orthosis.

Regarding the long-term effect on the parameter of pain, the group that received only Spinomed demonstrated an advantage. The X-ray results support this. Wearing an orthosis resulted in less collapse regardless of whether it was combined with a prior balloon kyphoplasty. Although kyphoplasty involves initial straightening of the affected vertebra, which is stabilised with cement, this is just a local operation on only the vertebra in question. However, in the case of osteoporosis, the entire spine is affected, meaning wearing an orthosis corresponds to a systemic reaction. The muscles are strengthened not only segmentally, but also along their entire lengths, which facilitates stabilisation of the spinal posture. This reduces incorrect posture and avoids affecting the nerves. This may trigger a lessening of the potential for pain.

As described in several studies, patients showed a significantly faster reduction in pain directly following balloon kyphoplasty $[11,19]$. The exact cause has not yet been completely determined. There is discussion of a 'cement phenomenon' such as heat or stabilisation, as well as improvement to the sagittal balance by straightening the spine. This advantage cannot be maintained over the long term. After 6 months, there was no longer any significant difference between the therapy groups. If conservative and surgical therapy seek to achieve similar long-term results, it seems that a detailed explanation to patients regarding everyday life is eminently important. This should explicitly address possible risks that must be considered in connection to a faster reduction in pain.

It would be useful to have further radiological long-term research with a sufficiently large population under study. Individual case studies and histological examinations of vertebral compounds following kyphoplasty or conservative treatment resulting from autopsies might also be helpful. Here, in addition to the existing animal models, it may also be possible to acquire human data through the progression of healing in osteoporotic vertebrae.

\section{Conflict of Interest}

All authors declare that they have no conflicts of interest.

\section{Compliance with Ethical Policies}

This study of number 140_15B at FAU Erlangen has received a positive vote from the Ethics Commission.

\section{References}

1. Burge R, Dawson-Hughes B, Solomon DH, Wong JB, King A, et al. (2007) Incidence and economic burden of osteoporosis-related fractures in the United States, 2005-2025. J Bone Miner Res 22(3): 465-475.

2. Silverman SL, Minshall ME, Shen W, Harper KD, Xie S (2001) The relationship of health-related quality of life to prevalent and incident vertebral fractures in postmenopausal women with osteoporosis: Results from the Multiple Outcomes of Raloxifene Evaluation Study Arthritis \& Rheumatism 44(11): 2611-2619.

3. Kado DM, Browner WS, Palermo L, Nevitt MC, Genant HK, et al. (1999) Vertebral fractures and mortality in older women: A prospective study. Study of Osteoporotic Fractures Research Group. Arch Intern Med 159(11): 1215-1220.

4. Lovi A, Teli M, Ortolina A, Costa F, Fornari M, et al. (2009) Vertebroplasty and kyphoplasty: Complementary techniques for the treatment of painful osteoporotic vertebral compression fractures. A prospective non-randomised study on 154 patients. Eur Spine J 18 Suppl 1: 95-101.

5. Anselmetti GC, Bernard J, Blattert T, Court C, Fagan D, et al. (2013) Criteria for the appropriate treatment of osteoporotic vertebral compression fractures. Pain Physician 16(5): E519-30.

6. Capozzi A, Scambia G, Pedicelli A, Evangelista M, Sorge R, et al. (2017) Clinical management of osteoporotic vertebral fracture treated with percutaneous vertebroplasty. Clin Cases Miner Bone Metab 14(2): 161-166.

7. Pfeifer M, Kohlwey L, Minne HW (2005) Die Rückenorthesen Spinomed und Spinomed active verbessern Körperhaltung, Rumpfmuskelkraft und Lebensqualität bei Frauen mit Osteoporose der Wirbelsäule: Ergebnisse einer prospektiven, randomisierten und kontrollierten Studie. Phys Med Rehab Kuror 15(04).

8. Riesner HJ, Kiupel K, Lang P, Stuby F, Friemert B, et al. (2016) Klinische Bedeutung von Zementleckagen nach Radiofrequenzkyphoplastie vs. Ballonkyphoplastie bei Wirbelkörperfrakturen - eine prospektive randomisierte Studie. Z Orthop Unfall 154(4): 370-376.

9. Bouza C, López T, Magro A, Navalpotro L, Amate JM (2006) Efficacy and safety of balloon kyphoplasty in the treatment of vertebral compression fractures: A systematic review. Eur Spine J 15(7): 10501067.

10. McCall T, Cole C, Dailey A (2008) Vertebroplasty and kyphoplasty: A comparative review of efficacy and adverse events. Curr Rev Musculoskelet Med 1(1): 17-23.

11. Kurra S, Metkar U, Lieberman IH, Lavelle WF (2018) The Effect of Kyphoplasty on Mortality in Symptomatic Vertebral Compression Fractures: A Review. Int J Spine Surg 12(5): 543-548.

12. Weiss M (ed) (1997) Rehabilitation durch Sport: 1. Internationaler Kongreß des Deutschen Behinderten-Sportbundes 1995. $1^{\text {st }}$ ed. Marburg, Kilian.

13. Pfeifer M, Kohlwey L, Begerow B, Minne HW (2011) Effects of two newly developed spinal orthoses on trunk muscle strength, posture, and quality-of-life in women with postmenopausal osteoporosis: A randomized trial. Am J Phys Med Rehabil 90(10): 805-815.

14. Ware J, Kosinski M, Keller SD (1996) A 12-Item Short-Form Health Survey: Construction of scales and preliminary tests of reliability and validity. Med Care 34(3): 220-233. 
15. Morfeld M, Dietsche S, Bürger W, Koch U (2003) Der SF-12 - Das Problem der Missing Data. Diagnostica 49(3): 129-135.

16. Gandek B, Ware JE, Aaronson NK, Apolone G, Bjorner JB, et al. (1998) Cross-validation of item selection and scoring for the SF-12 Health Survey in nine countries: Results from the IQOLA Project. International Quality of Life Assessment. J Clin Epidemiol 51(11): 1171-1178.

17. Berlemann U, Franz T, Orler R, Heini PF (2004) Kyphoplasty for treatment of osteoporotic vertebral fractures: A prospective nonrandomized study. Eur Spine J 13(6): 496-501.
18. Pflugmacher R, Taylor R, Agarwal A, Melcher I, Disch A, et al. (2008) Balloon kyphoplasty in the treatment of metastatic disease of the spine: A 2-year prospective evaluation. Eur Spine J 17(8): 1042-1048.

19. Wong CC, McGirt MJ (2013) Vertebral compression fractures: A review of current management and multimodal therapy. J Multidiscip Healthc 6: 205-214.

\section{Your next submission with Juniper Publishers will reach you the below assets}

- Quality Editorial service

- Swift Peer Review

- Reprints availability

- E-prints Service

- Manuscript Podcast for convenient understanding

- Global attainment for your research

- Manuscript accessibility in different formats ( Pdf, E-pub, Full Text, Audio)

- Unceasing customer service

Track the below URL for one-step submission https://juniperpublishers.com/online-submission.php 